Check for updates

Cite this: RSC Adv., 2017, 7, 40371

Received 8th June 2017

Accepted 8th August 2017

DOI: $10.1039 / \mathrm{c} 7 \mathrm{ra06447k}$

rsc.li/rsc-advances

\section{Novel highly stable $\beta$-cyclodextrin fullerene mixed valent Fe-metal framework for quick Fenton degradation of alizarin $\uparrow$}

\author{
Aniruddha Gogoi, ${ }^{\mathrm{a}}$ Madhukar Navgire, ${ }^{\mathrm{b}}$ Kanak Chandra Sarma ${ }^{\mathrm{a}}$ \\ and Parikshit Gogoi (D)*d
}

$\beta$-Cyclodextrin ( $\beta$-CD) supported magnetic nanoscaled fullerene/ $\mathrm{Fe}_{3} \mathrm{O}_{4}$ (CDFMNPs) and fullerene/ $/ \mathrm{Fe}_{3} \mathrm{O}_{4}$ (FMNPs) composites were prepared and characterized. These composites can be utilized as heterogeneous catalysts for the Fenton oxidation reaction to degrade alizarin in aqueous solutions. The saturation magnetization $\left(M_{\mathrm{s}}\right)$ value of quasi-spherical CDFMNPs was found to be $13.16 \mathrm{emu} \mathrm{g}^{-1}$ and their diameter was in the range of 25-30 nm. The catalytic activities of the prepared materials were tested with varying conditions of $\mathrm{pH}$, amount used and the concentration of $\mathrm{H}_{2} \mathrm{O}_{2}$ for degradation of alizarin at room temperature. The exceptionally high degradation efficiency of CDFMNPs was observed for alizarin at $\mathrm{pH} 3$ with $2.0 \mathrm{~g} \mathrm{~L}^{-1}$ catalyst and $25 \mathrm{mM}$ of $\mathrm{H}_{2} \mathrm{O}_{2}$. The increased oxidative degradation efficiency is attributed mainly to the formation of active hydroxyl radicals $\left({ }^{\circ} \mathrm{OH}\right)$ on the surface of the catalyst, which are generated by the active decomposition of $\mathrm{H}_{2} \mathrm{O}_{2}$ by the solid heterogeneous catalyst and the promoting effect of $\beta-C D$. CDFMNPs can be magnetically separated and the catalyst was found to be reusable and stable for five successive runs with no significant loss of catalytic activity. In the magnetic environment of $\mathrm{Fe}_{3} \mathrm{O}_{4}$ nanoparticles, fullerene has a crucial role to enhance the activity by increasing the stability with nominal iron leaching. Based on mass analysis of alizarin degradation, the formation of aliphatic acids and monocyclic compounds through phthalic anhydride and di-methyl phthalate established the proposed degradation path.

\section{Introduction}

The ever increasing pollution of water and soil by different industries, agricultural and domestic activities has been a major concern with respect public health due to recalcitrant toxic organic pollutants including dyes. Effluents from these activities have a high toxic organic content, color strength and resistant to degradation by light, chemicals and biological treatment., ${ }^{\mathbf{1} 2}$ Most of these compounds are responsible for numerous diseases, including cancer, due to their toxicity as mentioned by the European community and US Environmental protection agency. ${ }^{3}$ Therefore, wastewater treatment is essential before discharge into the environment. Numerous methods based on adsorption, photocatalytic degradation, ion exchange

${ }^{a}$ Department of Instrumentation \& USIC, Gauhati University, Guwahati 781014, Assam, India

${ }^{b}$ Department of Chemistry, Jijamata College of Science \& Arts, Bhende, Ahmadnagar, Maharastra, India

${ }^{c}$ Department of Chemistry, Nowgong College, Nagaon 782001, Assam, India. E-mail: parikk100@gmail.com

${ }^{d}$ School of Chemical and Biomolecular Engineering, Renewable Bioproducts Institute, Georgia Institute of Technology, Atlanta, Georgia, 30318, USA

$\dagger$ Electronic supplementary information (ESI) available. See DOI: 10.1039/c7ra06447k and advanced oxidation process (AOP) viz. Fenton oxidation, etc. have been adopted to eliminate these dyes and stable organic pollutants..$^{2,4-8}$ In spite of these methods, there is an urgent environmental need to develop more effective catalytic systems for degradation of pollutants. Fenton oxidation processes consisting of iron $\left(\mathrm{Fe}^{2+} / \mathrm{Fe}^{3+}\right)$ in heterogeneous phase and $\mathrm{H}_{2} \mathrm{O}_{2}$ would be the better choice. Unlike other oxidation processes, the generation of hydroxyl radicals in the Fenton process is from ferrous ions and hydrogen peroxide in aqueous solution. Besides this fact, the catalytic activities of heterogeneous Fenton systems depend on numbers of other parameters; mainly solution $\mathrm{pH}$, catalyst dosage, substrate concentration, $\mathrm{H}_{2} \mathrm{O}_{2}$ concentration and reaction time..$^{9-11}$

In the recent years, magnetic nanoparticles with low iron dissolution have gained attention as a catalyst for the degradation of organic dyes due to their remarkable features such as a large specific surface area and easy recovery of catalyst. ${ }^{12}$ The application of magnetic $\mathrm{Fe}_{3} \mathrm{O}_{4}$ particles are limited in different media as it has less number of surface active functional groups, tend to aggregate, formation of clusters and iron leaching which reduce their activity and stability. ${ }^{13}$ Thus, surface modification of $\mathrm{Fe}_{3} \mathrm{O}_{4}$ is essential and choosing the right candidate to enhanced stability of the $\mathrm{Fe}_{3} \mathrm{O}_{4}$ is a challenge, depending on the type of application. To overcome these limitations, some 
studies have reported the use of support materials such as clays, Nafion, activated carbon, zeolite, fullerene, carbon nanotubes, silica, polymers, metal oxides etc. ${ }^{\mathbf{1 1 , 1 3 - 2 0}}$ To keep iron in heterogeneous phase, use of carbon based materials are the advantageous due to its unique catalytic properties including the stability in acidic medium and higher temperature. ${ }^{21}$ Jaafarzadeh et al. reported the Fenton oxidation of tetracycline, catalyzed by powder activated carbon/ $\mathrm{Fe}_{3} \mathrm{O}_{4}$ hybrid composite with good stability of the catalyst within $4 \mathrm{~h} .{ }^{22}$ Nidheesh et al. found that iron loaded on activated carbon can effectively degrade rhodamin $\mathrm{B}$ in aqueous medium by Fenton process. ${ }^{23}$ Degradation of phenol by carbon supported Fe catalyst ${ }^{24}$ and orange II removal by Fe supported on carbon nanotubes ${ }^{25}$ showed good catalytic activities, but with less stability of the catalyst in terms of the high amount of Fe leaching in the former case after the reaction. Despite some progresses have been made so far, the industrial application of heterogeneous Fenton catalyst is still limited. Our strategy is to develop a magnetically recoverable, decently stable catalytic system with high catalytic activity towards dye degradation in the absence of light irradiation.

Fullerene $\left(\mathrm{C}_{60}\right)$ is a hollow sphere of carbon, which has a stable cage structure with high electron affinity (can accept up to six electrons) and resistant to oxidation. It has unique properties to form composites with various materials, ability to trap substances inside the cage and to act as a photo catalyst etc. $^{26-28}$ Encapsulation of fullerene to metal oxide provides ability to oxide surface by resisting air oxidation and maintains good magnetic properties. Synthetic strategies to produce nanocomposites of fullerene and magnetic iron oxide nanoparticles have been reported recently. Iron oxide forms strong colloidal assembly with fullerene at various $\mathrm{pH}$ on air-water interface. Zerovalent iron-fullerene nanocomposite system was reported to produce reactive oxygen species and $\mathrm{O}_{2}$, both in the presence and absence of UV light at near neutral $\mathrm{pH}$ for bacterial inactivation. , $^{\mathbf{2 9}, 30}$ It is expected that binding of fullerene with iron oxide likely to minimize iron precipitation through co-ordination. In this context, we hypothesized that doping of fullerene to magnetic nanoparticles will enhance the stability and generate reactive oxygen species (ROS) in the presence of $\mathrm{H}_{2} \mathrm{O}_{2}$ to act as a heterogeneous catalyst without UV light. Further, for surface modification and to increase the activity of the catalyst, cyclodextrin was found to be one of the suitable material. ${ }^{31} \beta$-Cyclodexrtin ( $\beta$-CD) is a cyclic oligosaccharide with 7 membered cyclic D-glucose units connected through $\alpha-(1 \rightarrow 4)$ glucosidic linkages to form a cone shaped cylindrical cavity. Cyclodextrin can form self-assembled organic-inorganic framework with metal oxide surface by forming hydrogen bond through hydroxyl groups of the cyclodextrin. It also forms host-guest inclusion complexes selectively with different organic molecules through their hydrophobic cavity. The host-guest interactions are mainly hydrogen bonding and van der Waals forces between $\beta$-CD and organic molecules. ${ }^{32-36}$ Therefore, the $\beta$-CD and fullerene $/ \mathrm{Fe}_{3} \mathrm{O}_{4}$ expected to simplify the stability and activity issues related to degradation of dyes in Fenton system.

In the present study, highly stable $\beta$-CD coated fullerene/ $\mathrm{Fe}_{3} \mathrm{O}_{4}$ nanostructures were prepared via a facile co-precipitation method and used as a Fenton catalyst for the degradation of alizarin dye from aqueous solution. Alizarin, also called 1,2dihydroxyanthraquinone belong to madder plant with formula $\mathrm{C}_{14} \mathrm{H}_{8} \mathrm{O}_{4}$ is a major pigment in textile industries. ${ }^{37-39}$ To the knowledge of the authors, no studies have been reported till now on the heterogeneous Fenton degradation of alizarin from aqueous solutions using $\beta$-CD coated fullerene $/ \mathrm{Fe}_{3} \mathrm{O}_{4}$ nanocomposite at optimum mild operating conditions.

\section{Experimental section}

\subsection{Preparation of fullerene $/ \mathrm{Fe}_{3} \mathrm{O}_{4}$}

Fullerene $/ \mathrm{Fe}_{3} \mathrm{O}_{4}$ nanoparticles (MFNPs) were prepared by conventional co-precipitation method. The reaction mixture was obtained by dissolving $0.86 \mathrm{~g}$ of $\mathrm{FeCl}_{2} \cdot 4 \mathrm{H}_{2} \mathrm{O}$ (Merck), $2.63 \mathrm{~g}$ of $\mathrm{FeCl}_{3} \cdot 6 \mathrm{H}_{2} \mathrm{O}$ (Merck) and fine powdered fullerene (1 wt\%) $\left(\mathrm{C}_{60}\right.$, Sigma-Aldrich, $\left.99.5 \%\right)$ in $\mathrm{mL}$ of de-ionized water with constant stirring. $\mathrm{NH}_{4} \mathrm{OH}$ solution was added dropwise to maintain the $\mathrm{pH}=8$. The mixture was stirred for $12 \mathrm{~h}$ for complete precipitation and then kept $12 \mathrm{~h}$ for aging. The resultant precipitate was magnetically separated, washed several times with deionized water and dried in oven at $90{ }^{\circ} \mathrm{C}$ for $12 \mathrm{~h}$.

\subsection{Preparation of $\beta$-cyclodextrin-fullerene $/ \mathrm{Fe}_{3} \mathrm{O}_{4}$}

The $\beta$-CD fullerene $/ \mathrm{Fe}_{3} \mathrm{O}_{4}$ nanoparticles (CDMFNPs) were also prepared by simple method. The synthesized MFNPs $(1.8 \mathrm{~g})$ were mixed with $(0.5 \mathrm{~g})$ of $\beta$-cyclodextrin (Himedia) in $75 \mathrm{~mL}$ of deionized water with constant stirring. The mixture was kept under constant stirring for $24 \mathrm{~h}$ and then kept another $24 \mathrm{~h}$ for aging. The resultant particles were separated magnetically from residual solution and washed several times with deionized water and dried in oven at $90{ }^{\circ} \mathrm{C}$ for $12 \mathrm{~h}$.

\subsection{Characterization of $\beta$-cyclodextrin-fullerene $/ \mathrm{Fe}_{3} \mathrm{O}_{4}$}

The formation of fullerene $/ \mathrm{Fe}_{3} \mathrm{O}_{4}$ (FMNPs) and $\beta$-cyclodextrin coated fullerene/ $\mathrm{Fe}_{3} \mathrm{O}$ (CDFMNPs) were investigated systematically by different sophisticated analytical techniques.

Powder X-ray diffraction (XRD) measurements were observed by using a Bruker/D2 phaser, Germany; diffractometer ( $\mathrm{Cu} \mathrm{K} \alpha$ radiation source, $\lambda=1.542 \AA$, operates at $30 \mathrm{kV}$ and $10 \mathrm{~mA})$. The sample scan was done over a diffraction angle of $2 \theta$ in the range of $20-80^{\circ}$ in $0.02^{\circ}$ step scan with exposure time of $2 \mathrm{~s}$.

Fourier transform infrared spectroscopy (FTIR) measurements were performed with a Perkin Elmer, USA/Spectrum Two; spectrometer using $\mathrm{KBr}$ pellet over a range of $4000-400 \mathrm{~cm}^{-1}$. Same setup is used to perform pyridine-FTIR study of the synthesized samples.

Magnetic measurements were carried out using a vibrating sample magnetometer (VSM; Lakeshore 7410).

Field Emission Scanning Electron Microscopy (FESEM) study was performed on Carl Zeiss-Sigma instrument. Transmission Electron Microscopy (TEM) and High Resolution TEM (HRTEM) characterization was done on JEM-2010 (JEOL), instrument.

Thermogravimetric analysis (TGA) was performed by using a Mettler Toledo (TGA/SDTA $581^{\mathrm{e}}$ ) thermogravimetric analyzer 
from $30-700{ }^{\circ} \mathrm{C}$ with a heating rate of $10{ }^{\circ} \mathrm{C} \mathrm{min}^{-1}$ under nitrogen atmosphere.

Electron Paramagnetic Resonance (EPR) studies were performed by using a JEOL (JES-FA200) EPR spectrometer.

UV-vis DRS (Diffuse Reflectance Spectra) measurements were performed by Perkin Elmer (Lambda 750 UV/Vis/NIR) spectrophotometer using a diffuse reflectance attachment. $\mathrm{BaSO}_{4}$ matrix was used as a reference to record the spectra in the range of 200-800 nm.

The absorption spectra were measured using a Shimadzu/ UV-1800 UV-vis spectrophotometer to determine band gap energy and degradation study.

\subsection{Catalytic test study}

The performances of the prepared catalyst were tested by carrying out batched degradation reaction of alizarin (SigmaAldrich, 97\%) at room temperature. Typically, samples for alizarin degradation system were prepared by adding required amount of catalyst to a solution containing known amount of dyes $(10 \mathrm{mM})$ in a conical flask $(100 \mathrm{~mL})$, ultra-sonicated to make a homogeneous suspension followed by constant stirring. To initiate the reactions a known dosage of $\mathrm{H}_{2} \mathrm{O}_{2}$ was added to each reaction mixture. The catalyst amount, $\mathrm{H}_{2} \mathrm{O}_{2}$ and $\mathrm{pH}$ concentrations were varied systematically from $0.25 \mathrm{~g} \mathrm{~L}^{-1}$, 5-25 mM and pH 3-10 respectively at an alizarin concentration of $10 \mathrm{mM}$. The various $\mathrm{pH}$ conditions were maintained by using $1 \mathrm{M} \mathrm{NaOH}$ or $\mathrm{H}_{2} \mathrm{SO}_{4}$. The progress of the reaction was monitored and determined by measuring absorbance at a regular interval by taking aliquots of the reaction mixture to evaluate the catalytic activity in the range of $300-800 \mathrm{~nm}$. The change in absorbance with respect to time of alizarin degradation $\left(\lambda_{\max }\right.$ at 497-526 nm) was measured for all sets of catalyst. The experiments were performed in triplicate to check the reproducibility of results and the values are presented as means and standard deviation. The leaching of iron from the catalyst surface at the optimum reaction conditions during the process of degradation of alizarin was studied.

$\mathrm{The} \mathrm{Fe}^{2+}$ ion concentration in solution was measured using 1,10-phenanthroline method by spectrophotometrically at $510 \mathrm{~nm}$. The total dissolved iron was also measured by same method using hydroxylamine hydrochloride as a reducing agent for the experiment. ${ }^{18,40,41}$

The degraded sample was filtered with $0.02 \mu \mathrm{m}$ filter paper after the reaction and Liquid Chromatography Mass Spectrometry (LC-MS) analysis was carried out to determine the intermediate and final products of alizarin degradation. Control and degraded sample of alizarin was analyzed by the Agilent 6520 series Accurate-Mass Q-TOF LC/MS spectrometer. In this LC/MS system, Liquid Chromatography (LC) part is coupled with High Resolution Mass Spectrometer (HRMS). Following were the operating conditions for the system: first the instrument was calibrated with a standard calibrated solution for ESI$(+)$ mode in the mass range of $50-500 \mathrm{~m} / \mathrm{z}$ to record mass spectra within this range. The system was operated on electrospray ionization (ESI), positive $(+)$ mode. The column used for separation of the products was C18 (Agilent Eclipse plus, $3.5 \mu \mathrm{m}$,
$4.6 \times 100 \mathrm{~mm}$ ). The solvent used as mobile phase was a mixture of acetonitrile water with a flow rate of $3 \mathrm{~mL} \mathrm{~min}^{-1}$. A volume of $20 \mu \mathrm{L}$ samples was loaded with a syringe to inject through capillary column. Nitrogen gas used as nebulizer gas and collision cell gas (nitrogen) was $99.999 \%$ pure. The other parameters were set as standard for the system. The degradation products identified by LC-MS studies were verified by standard mass spectra database, literature and comparing with MS spectra of those of known chemicals.

\section{Results and discussions}

\subsection{Characterization of magnetic nanoparticles}

3.1.1. XRD analysis. The structural characterization of the synthesized materials was carried out using X-ray diffraction (XRD). Fig. 1 shows the XRD patterns of FMNPs and CDFMNPs. It has all the major diffraction peaks corresponding to the lattice planes of (220), (311), (400), (422), (511) and (440), which confirm the presence of $\mathrm{Fe}_{3} \mathrm{O}_{4}$ in the composite (Fig. S1 of ESI, $\dagger$ for comparison). The values are narrowly matched with standard data (JCPDS file PDF no. 65-3107). Both the XRD patterns clearly show two prominent diffraction peaks for fullerene at $2 \theta$ values of 17.6 and 21 corresponding to the lattice plane of (220) and (311), respectively. ${ }^{28,42}$ The peaks at $2 \theta$ of $29.44,39.0,47.3$, 52.8 and 57.5 corresponding to the crystal planes (421), (532), (642), (654) and (761), indicate the existence of fullerene or carbon substrate in cubic crystalline symmetry. All the values for fullerene are closely matched with the JCPDS card no. 791715. These peaks confirm the presence of fullerene in $\mathrm{Fe}_{3} \mathrm{O}_{4}$ nanoparticles. Usually $\beta$-CD does not give any diffraction peaks due to the amorphous nature or fine dispersion of it onto metal oxide surfaces. ${ }^{43}$ The XRD patterns of FMNPs and CDFMNPs in Fig. 1 are nearly same which indicating that no deformation of crystal structure of FMNPs after incorporation of $\beta$-CD. It was also observed that after incorporating $\beta$-CD in the FMNPs

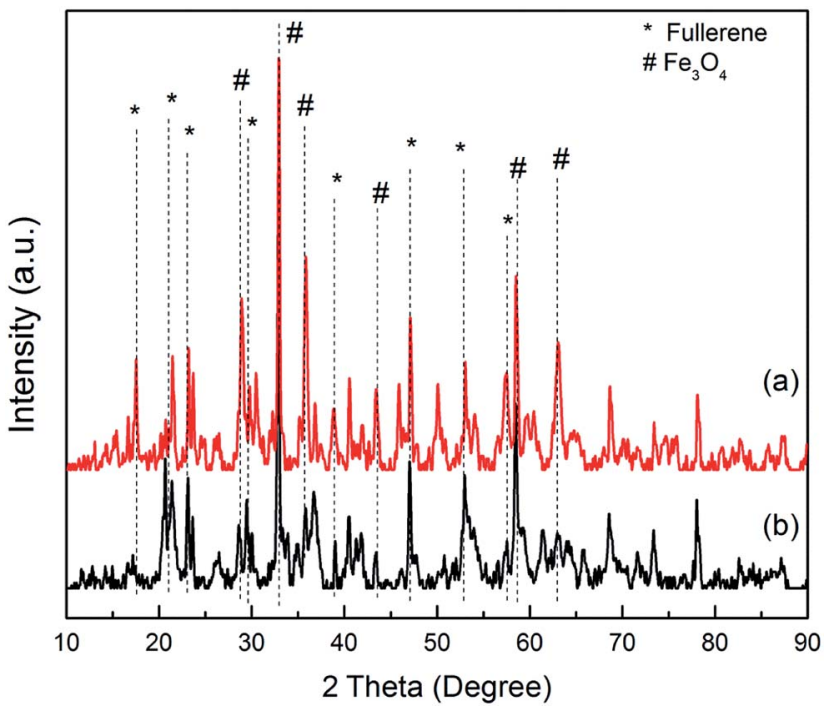

Fig. 1 XRD spectrum of (a) fullerene/ $/ \mathrm{Fe}_{3} \mathrm{O}_{4}$ (FMNPs) and (b) $\beta-\mathrm{CD}$ fullerene/ $\mathrm{Fe}_{3} \mathrm{O}_{4}$ (CDFMNPs) nanocomposite. 
composite the intensity of the XRD peaks decreased, indicating the presence of $\beta-\mathrm{CD}$ in the composite. The decrease in the intensity of the XRD peaks may be due to decreases in the crystalline nature of CDFMNPs. Significantly no detectable peaks were observed for $\beta$-CD in the XRD pattern of CDFMNPs but the small changes in the peak position of FMNPs with addition of $\beta$-CD confirms the complete incorporation of the $\beta$-CD in the CDFMNPs. Therefore, the prepared catalysts are mesoporous structure and simultaneously have the properties of iron oxide, fullerene and $\beta$-CD.

3.1.2. FT-IR analysis. The coating of $\beta$-CD over FMNPs is confirmed by the FTIR study. Fig. 2 shows the FTIR spectra of the synthesized $\beta$-CD, FMNPs and CDFMNPs. Peaks at 3153 $\mathrm{cm}^{-1}$ and $1640 \mathrm{~cm}^{-1}$ can be ascribed to bending and stretching vibration of the adsorbed water molecules. Two absorption bands at $629 \mathrm{~cm}^{-1}$ and $562 \mathrm{~cm}^{-1}$ are produced from the splitting of the characteristic stretching vibration of $\mathrm{Fe}-\mathrm{O}$ bond of $\mathrm{Fe}_{3} \mathrm{O}_{4}$ at around $574 \mathrm{~cm}^{-1}$ for both the catalysts. ${ }^{18}$ Other peaks at $1405 \mathrm{~cm}^{-1}$ and $1004 \mathrm{~cm}^{-1}$ can be assigned as $-\mathrm{C}=\mathrm{C}-$ and $-\mathrm{C}-$ $\mathrm{R}$ stretching vibrations, respectively. For CDFMNPs, the absorption bands in the range of $1200-900 \mathrm{~cm}^{-1}$ with new peaks are characteristic for $\beta-C D$. The peaks at $1140 \mathrm{~cm}^{-1}$ and $1084 \mathrm{~cm}^{-1}$ can be assigned to coupled $\nu(\mathrm{C}-\mathrm{C} / \mathrm{C}-\mathrm{O})$ vibration and antisymmetric glycosidic $\nu(\mathrm{C}-\mathrm{O}-\mathrm{C})$ vibration, respectively. ${ }^{33,36}$ Some absorption bands of FMNPs also present in CDFMNPs with a little shift in position, suggested the successful incorporation of $\beta-C D$ on the surface of the FMNPs.

3.1.3. Magnetic properties measurement. Magnetic measurements for the synthesized materials were carried out using a vibrating sample magnetometer at room temperature are shown in Fig. 3. The presence of $(\mathrm{MH})$ loops indicates ferromagnetic nature of the synthesized materials at room temperature. The magnetic-hysteresis loops reveal negligible coercivity for $\mathrm{Fe}_{3} \mathrm{O}_{4}$, FMNPs and CDFMNPs with saturation magnetization value $\left(M_{\mathrm{s}}\right)$ of $58.0,21.49$ and $13.16 \mathrm{emu} \mathrm{g}^{-1}$

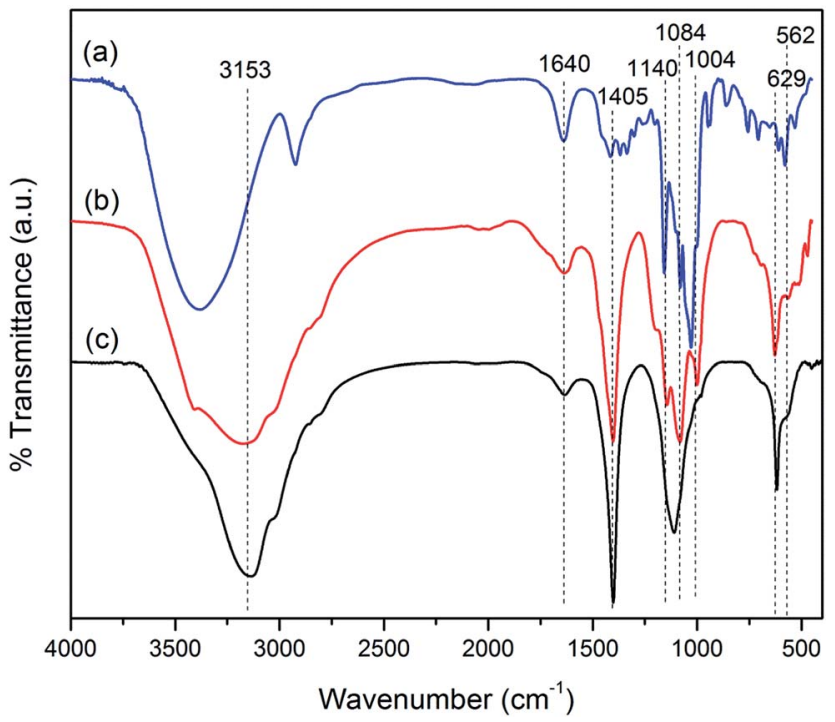

Fig. 2 FT-IR spectra of (a) $\beta$-CD (b) $\beta$-CD-fullerene/ $/ \mathrm{Fe}_{3} \mathrm{O}_{4}$ (CDFMNPs) and (c) fullerene $/ \mathrm{Fe}_{3} \mathrm{O}_{4}$ (FMNPs) nanocomposite.

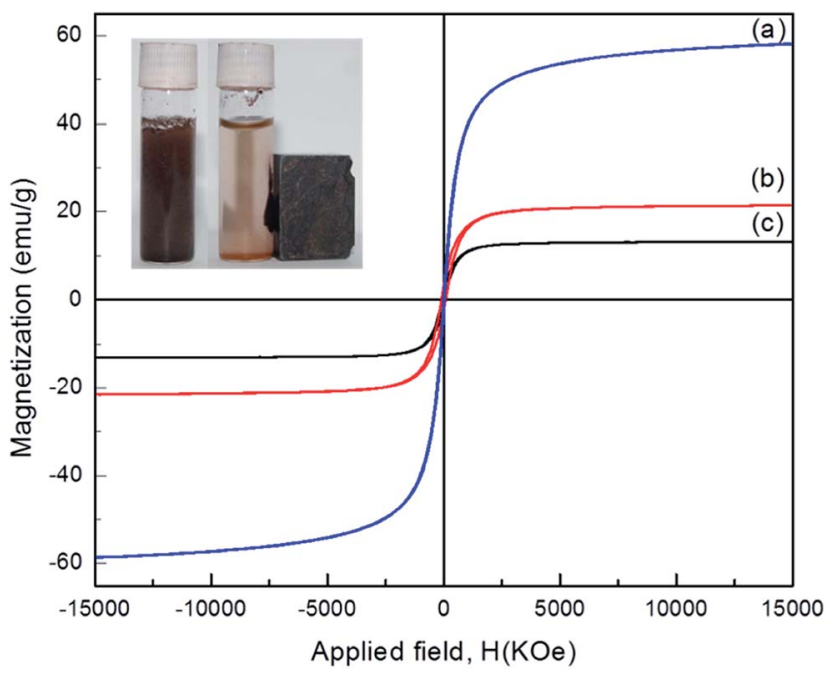

Fig. 3 Magnetic hysteresis of (a) $\mathrm{Fe}_{3} \mathrm{O}_{4}$ (b) fullerene/ $/ \mathrm{Fe}_{3} \mathrm{O}_{4}$ (FMNPs) (c) $\beta$-CD-fullerene/ $\mathrm{Fe}_{3} \mathrm{O}_{4}$ (CDFMNPs) nanocomposite and separation of catalyst using an external magnet (inset).

respectively. The differences in $M_{\mathrm{S}}$ values for all the compounds are attributed to the presence of fullerene and formation of heterostructure with nonmagnetic organic $\beta$-CD to exist as magneto crystalline anisotropy. The moderate magnetic property of both FMNPs and CDFMNPs indicates their excellent catalytic behavior in terms of magnetic separation and reusability after reaction. The lower magnetization value of CDFMNPs is due to the higher percentage of non-magnetic carbon and $\beta-\mathrm{CD}$ as compared to FMNPS composite. Though the $M_{\mathrm{S}}$ value is low for the CDFMNPs in comparison to bare $\mathrm{Fe}_{3} \mathrm{O}_{4}$ nanoparticle, the CDFMNPs can be easily separated with strong external magnet for reuse which is one of the important property of the reported catalyst. Fig. 3 (inset) shows the magnetic response of the CDFMNPs.

3.1.4. FE-SEM studies. The surface morphology of the prepared catalysts was studied by scanning electron microscopy. Fig. 4 shows the FESEM low and high resolutions images of the prepared FMNPs (Fig. 4(a and b)) and CDFMNPs (Fig. 4(c and d)). The figures clearly indicate crystalline structure of both the composites. From the Fig. 4(a and b) it can be seen that particle surface is smooth and assemblies are created because of the magnetic nature. On the other hand, Fig. 4(c and d) clearly indicates the surface modification after incorporating $\beta$ CD over FMNPs. Most of the particles are nearly spherical in shape with rough surface having crystalline nature. These surface morphology results are consistent with the above XRD results, indicating the presence of physical interactions between the fullerene and magnetite with surface active sites and inconformity with Rodriguez et al. who reported magnetic fullerene and activated carbon adsorbents for selective adsorption of azo dyes from aqueous solutions. ${ }^{27}$

3.1.5. TEM analysis. TEM and HRTEM studies were performed to understand the size and morphology of the synthesized sample. Bright field image of CDFMNPs in Fig. 5(a) shows the good dispersion of the semispherical nanoparticles in the size range of 25-30 nm. Fullerene and $\mathrm{Fe}_{3} \mathrm{O}_{4}$ binary composites 

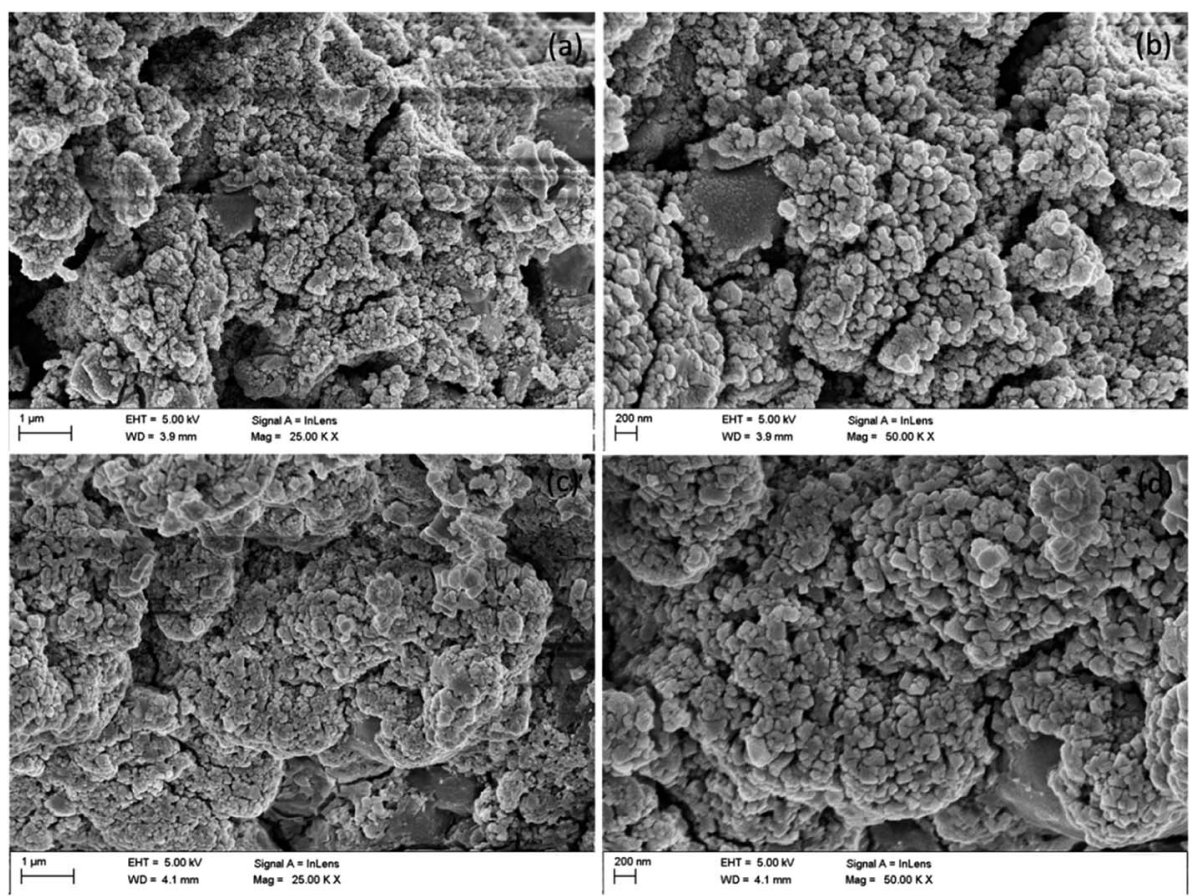

Fig. 4 FESEM images of ( $a$ and $b$ ) $\beta$-CD-fullerene/Fe ${ }_{3} \mathrm{O}_{4}$ (CDFMNPs) and (c and d) fullerene/Fe $\mathrm{O}_{4}$ (FMNPs) nanocomposite.

can be clearly seen in the TEM and HRTEM images in Fig. 5(b and c). The coating of $\beta$-CD is also clearly seen on the outer surface of the nanoparticles as shown in Fig. 5(c and d). From the IFFT pattern Fig. 5(e1), the lattice spacing was calculated as $0.25 \mathrm{~nm}$ corresponding to (311) plane of the crystalline $\mathrm{Fe}_{3} \mathrm{O}_{4}$ nanoparticle. Detailed information about the crystal plane can be obtained from the selected area electron diffraction (SAED) pattern as in Fig. 5(f). The lattice spacing calculated from the rings in the electron diffraction patterns is found to be $0.29 \mathrm{~nm}$ and $0.25 \mathrm{~nm}$ corresponds to the (220) and (311) crystal plane of $\mathrm{Fe}_{3} \mathrm{O}_{4}$ respectively. ${ }^{43}$ These results of TEM characterization are consistent with the earlier reports of characterization of nanoparticles. ${ }^{5}$ Further, TEM and HRTEM analysis indicates that fullerene likely to influence the morphology of the CDFMNPs thereby effect the reactivity towards the formation of hydroxyl radicals and overall stability of the system.
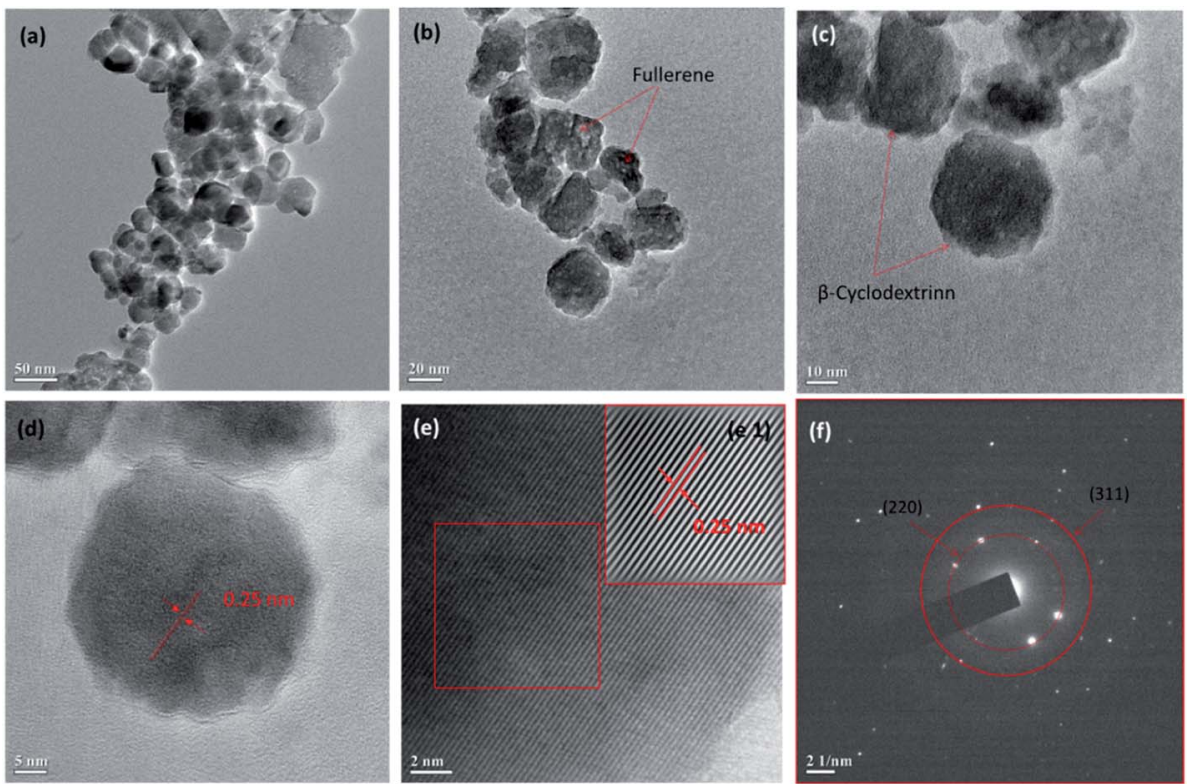

Fig. 5 TEM images (a) and (b); HRTEM images (c) HRTEM of single particle (d); HRTEM (e) and IFFT pattern (inset of e1); SEAD pattern (f) of $\beta$-CDfullerene $/ \mathrm{Fe}_{3} \mathrm{O}_{4}$ nanocomposite. 
3.1.6. TGA study. The conjugation of $\beta-C D$ on the surface of nanoparticles and presence of fullerene in CDFMNPs was confirmed by TGA study. The TGA thermograms for both the composites FMNPs and CDFMNPs are shown in Fig. S2 (ESI $\dagger$ ). It can be seen from the graph that both the curves have similar pattern, which indicate that the catalysts have similar thermal stability. CDFMNPs is slightly unstable than FMNPs up to $650{ }^{\circ} \mathrm{C}$ and thereafter both are thermally stable. The TGA thermogram of CDFMNPs exhibits three step weight loss between 300-650 ${ }^{\circ} \mathrm{C}$, leaving $\mathrm{Fe}_{3} \mathrm{O}_{4}$ nanoparticles and residual carbon. The first $11 \%$ weight loss up to $120{ }^{\circ} \mathrm{C}$ is due to evaporation of surface adsorbed water. The second weight loss starts from $200{ }^{\circ} \mathrm{C}$, it increases with increasing temperature and attains maximum weight loss of $54 \%$ at $450{ }^{\circ} \mathrm{C}$. This is due to the decomposition of remaining organic residue and decomposition of oxygen containing functional groups. While after $450{ }^{\circ} \mathrm{C}$ weight loss was due to decomposition of $\beta$-CD present in material. The final weight loss between $550-640{ }^{\circ} \mathrm{C}$ is mainly due to the progressive degradation of fullerene. Comparing both the curves, it was observed that the degradation of fullerene started little early in the CDFMNPs, which is due to the presence of $\beta-\mathrm{CD}$ in the composite. Thereafter the composite is stable.

For FMNPs, the $5 \%$ weight loss up to $120{ }^{\circ} \mathrm{C}$ is due to the surface bonded water molecules, second $35 \%$ weight loss between $200-450{ }^{\circ} \mathrm{C}$ is due to the decomposition of remaining organic residue, while after $450{ }^{\circ} \mathrm{C}$ due to the decomposition of oxygen containing functional groups. The final weight loss of $16 \%$ in the range of $580-650{ }^{\circ} \mathrm{C}$ is due to the degradation of fullerene. Thereafter, the composite is stable; it confirms strong binding between the fullerene and $\mathrm{Fe}_{3} \mathrm{O}_{4}$ present in FMNPs.

\subsubsection{Optical properties study}

$U V$-vis DRS analysis. To understand the optical properties of synthesized FMNPs and CDFMNPs, UV-visible DRS spectra were taken and the observed results are displayed in Fig. S3 (ESI $\dagger$ ). The absorption intensities of FMNPs were higher than CDFMNPs. For FMNPs two absorption bands were observed at $482 \mathrm{~nm}$ and $542 \mathrm{~nm}$ whereas for CDFMNPs only maximum absorption band appeared around $542 \mathrm{~nm}$, clearly indicates the change. The lower intensity of CDFMNPs band could be due to the change of crystalline size caused by the incorporation of $\beta$ CD.

$U V$-vis spectroscopy. The optical absorption spectral study is used to understand the electronic structure associated with the band gap of a material as electronic transition within the molecule is responsible for absorption to occur. Fig. S4(a \& c) $(\mathrm{ESI} \dagger)$ shows the observed optical absorption spectra in the range of 200-800 $\mathrm{nm}$ for FMNPs and CDFMNPs. For FMNPs, observed spectra have two distinct absorption bands, one at $301 \mathrm{~nm}$ of the UV region and another at $414 \mathrm{~nm}$ of the visible region. CDFMNPs spectra shows only one well defined absorption peak at $303 \mathrm{~nm}$, which clearly indicates that the change occurred, is due to the addition of $\beta$-CD. Using Tauc equation band gap energy $\left(E_{\mathrm{bg}}\right)$ can be calculated for both the catalyst. The equation is:

$$
(\alpha h \nu)^{2}=A\left(h \nu-E_{\mathrm{bg}}\right)
$$

where, $A$ is a constant; $\alpha, h$ and $\nu$ are the absorption coefficient, Plank constant and frequency respectively. By plotting the $(\alpha h \nu)^{2}$ versus $h \nu$ and extrapolation of the linear part of the curve to the $(\alpha h \nu)^{2}=0$, the $E_{\mathrm{bg}}$ for both the samples were calculated. Fig. S4(b \& d) (ESI $\dagger$ ) shows the Tauc plot for FMNPs and CDFMNPs. The band gap energies calculated form the Tauc plot were found to be $4.10 \mathrm{eV}$ and $3.35 \mathrm{eV}$ for FMNPs and CDFMNPs respectively. Both values are higher than the reported values for magnetite $\mathrm{Fe}_{3} \mathrm{O}_{4}$ nanoparticles $(0-3 \mathrm{eV})^{45}$ which were mainly due to the composite formation between $\mathrm{Fe}_{3} \mathrm{O}_{4}$ and fullerene for FMNPs and a combination of fullerene and $\beta$-CD for CDFMNPs respectively. This could be attributed to the structural change occurs within the lattice site due to defect or oxygen vacancy.

3.1.8. Electron paramagnetic resonance (EPR) study. Electron paramagnetic resonance (EPR) lines were measured for FMNPs and CDFMNPs at X-band (9.44 GHz) and shown in Fig. S5 (ESI $\dagger$ ). For both the samples broad and strong asymmetry single signals were obtained around the resonance magnetic field $\left(H_{\text {res }}\right)$ of 261 and 282 Gauss for FMNPs and CDFMNPs respectively. At room temperature, the observed intensity for FMNPs is more than three times the intensity of the CDFMNPs. The difference in intensity and signal width could be due to the magnetic loss after coating of $\beta$-CD over FMNPs. Additionally; spin disorder could be the reason for resonance line broadening which arises from the antiferromagnetic interaction of neighboring spins of the magnetic particles. ${ }^{46}$

3.1.9. Pyridine FTIR studies. The FTIR spectra of pyridine adsorbed on the surface of the FMNPs and CDFMNPs composites were shown in the Fig. S6 (ESI $\dagger$ ). The FTIR spectra show the Bronsted and Lewis acid site absorption bands for the composites. The characteristic absorption band for pyridine adsorption on the surface is shown at $1640 \mathrm{~cm}^{-1}$ and $1455 \mathrm{~cm}^{-1}$ corresponding to Bronsted and Lewis acidic sites respectively. The absorption peak at $1490 \mathrm{~cm}^{-1}$ can be attributed to the presence of both Bronsted and Lewis acidic sites. ${ }^{43}$

\subsection{Catalytic activity of $\beta$-cyclodextrin coated fullerene $/ \mathrm{Fe}_{3} \mathrm{O}_{4}$ nanocomposite}

The catalytic activity of the CDFMNPs was investigated for the degradation of alizarin at a planned reaction conditions. Fig. 6 shows the typical UV-vis degradation spectra of alizarin in the presence of $\mathrm{H}_{2} \mathrm{O}_{2}\left(\lambda_{\max }\right.$ at 497-526 nm) for $1 \mathrm{~h}$. Addition of CDFMNPs results in a progressive decrease of the typical alizarin absorption band with slight change in adsorption position, suggested the degradation of alizarin. Reaction with control experimental conditions showed that CDFMNPs without $\mathrm{H}_{2} \mathrm{O}_{2}$ or $\mathrm{H}_{2} \mathrm{O}_{2}$ without catalyst do not give alizarin degradation. Fig. 7 shows the alizarin degradation by $\mathrm{Fe}_{3} \mathrm{O}_{4}$, FMNPs and CDFMNPs with $2 \mathrm{~g} \mathrm{~L}^{-1}$ catalyst, $\mathrm{H}_{2} \mathrm{O}_{2}(25 \mathrm{mM})$ at $\mathrm{pH} 3$ where, alizarin concentration was $10 \mathrm{mM}$ at room temperature. It was found that CDFMNPs degrades alizarin almost completely (about 93\%) within $1 \mathrm{~h}$ and at same reaction condition FMNPs and $\mathrm{Fe}_{3} \mathrm{O}_{4}$ nanoparticles degrades only about $64 \%$ and $57 \%$ of the alizarin concentration, respectively. The higher degradation efficiency of the composite was due to the higher number of 


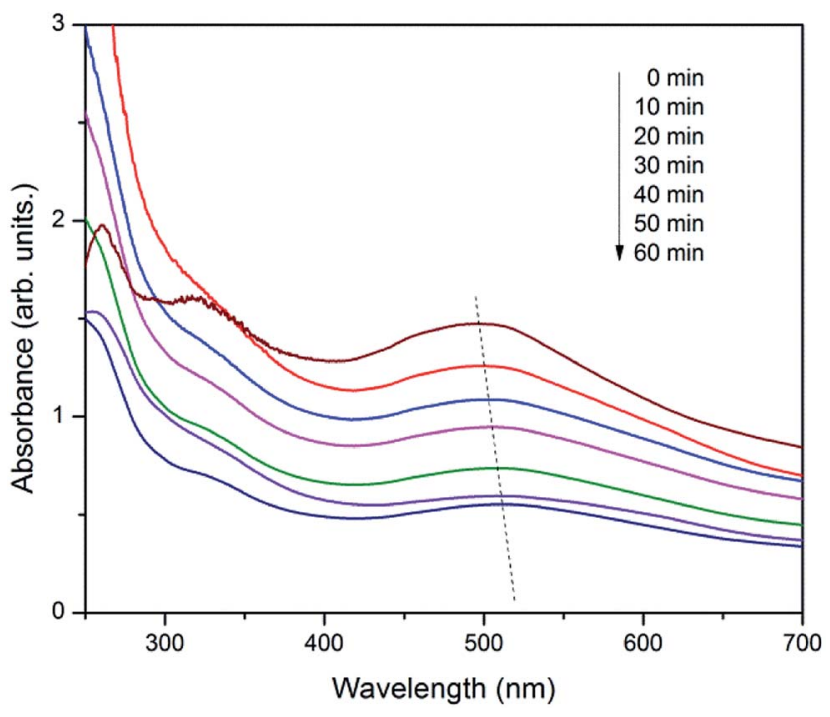

Fig. 6 UV-vis spectra showing the degradation of alizarin $\left(\lambda_{\max }\right.$ at 497-526 nm) by $\beta$-CD-fullarene $/ \mathrm{Fe}_{3} \mathrm{O}_{4}$ (CDFMNPs), reaction conditions: $\left[\mathrm{H}_{2} \mathrm{O}_{2}\right]=25 \mathrm{mM}$, catalyst $=2.0 \mathrm{~g} \mathrm{~L}^{-1}, \mathrm{pH}=3$, [alizarin] $=10 \mathrm{mM}$ at room temperature.

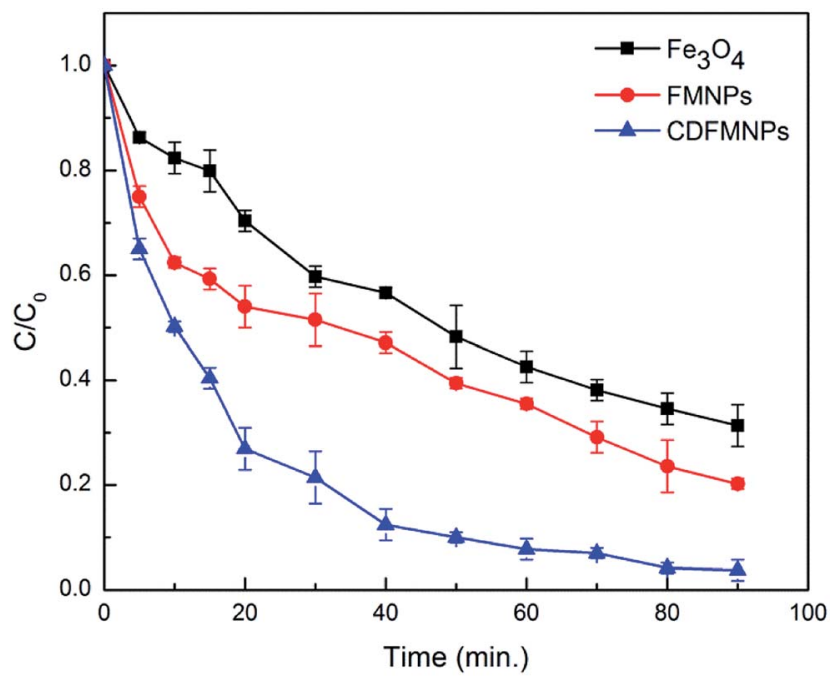

Fig. 7 Comparative degradation of alizarin by $\mathrm{Fe}_{3} \mathrm{O}_{4}, \mathrm{FMNPs}$ and CDFMNPs, reaction conditions: $\left[\mathrm{H}_{2} \mathrm{O}_{2}\right]=25 \mathrm{mM}$, catalyst $=2.0 \mathrm{~g} \mathrm{~L}^{-1}$, $\mathrm{pH}=3$, [alizarin] $=10 \mathrm{mM}$ at room temperature. The experiments were performed in triplicate and error bars show the standard deviation for the analyses.

surface active groups and more effective surface area provided by the addition of $\beta$-CD.

Reaction was carried out with varying amount of $\mathrm{H}_{2} \mathrm{O}_{2}$ concentration viz. $5 \mathrm{mM}, 10 \mathrm{mM}, 15 \mathrm{mM}, 20 \mathrm{mM}$ and $25 \mathrm{mM}$ to know the effect of $\mathrm{H}_{2} \mathrm{O}_{2}$ on Fenton reaction. Fig. 8 \& S7 (ESI $\dagger$ ) shows that the $25 \mathrm{mM} \mathrm{H}_{2} \mathrm{O}_{2}$ has the height degradation efficiency for $10 \mathrm{mM}$ of alizarin indicating that it directly depends on the concentration of hydroxyl radical produced from the reaction of $\mathrm{H}_{2} \mathrm{O}_{2}$ and $\mathrm{Fe}^{2+}$. In Fenton or Fenton like reactions the active species for degradation is hydroxyl radical and is

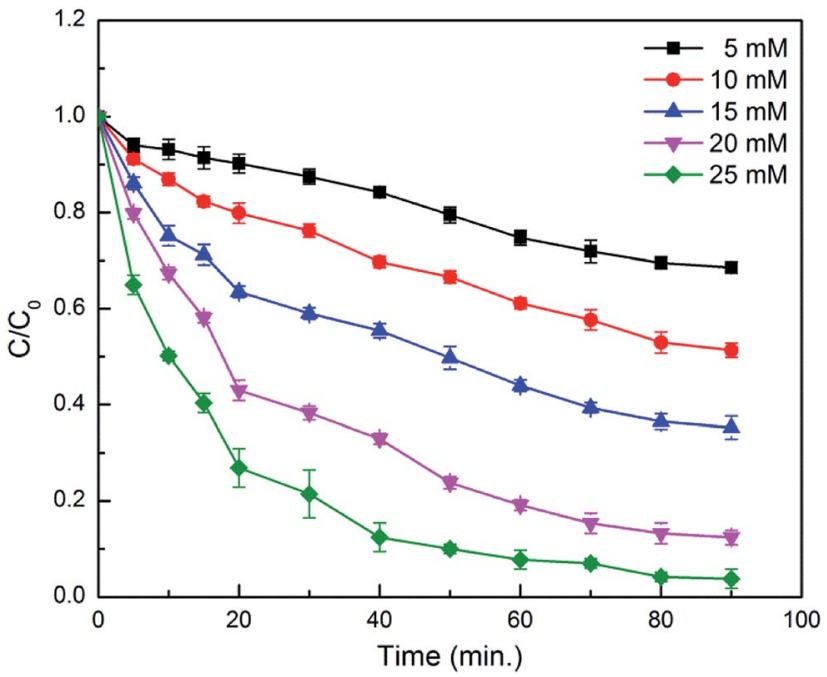

Fig. 8 Effect of $\mathrm{H}_{2} \mathrm{O}_{2}$ on degradation of alizarin by CDFMNPs, reaction conditions: catalyst $=2.0 \mathrm{~g} \mathrm{~L}^{-1}, \mathrm{pH}=3$, [alizarin] $=10 \mathrm{mM}$ at room temperature. The experiments were performed in triplicate and error bars show the standard deviation for the analyses.

formed during the electron transfer process of $\mathrm{Fe}^{2+}$ and $\mathrm{Fe}^{3+} .{ }^{37}$ $\mathrm{Fe}^{2+}$ initiates the reaction faster as compared to $\mathrm{Fe}^{3+}$ and series of reactions takes place quickly. Moreover, $\mathrm{Fe}^{3+}$ reacts with $\mathrm{H}_{2} \mathrm{O}_{2}$ to regenerate $\mathrm{Fe}^{2+}$ to reuse it in the Fenton reaction again. ${ }^{5,48} \mathrm{We}$ have performed the reactions at $\mathrm{pH} 3$, as in acidic conditions $\mathrm{H}_{2} \mathrm{O}_{2}$ is more stable. In basic conditions, the oxidative ability of $\mathrm{H}_{2} \mathrm{O}_{2}$ decreases because of its decomposition to produce water and oxygen. ${ }^{11}$ The use of low $\mathrm{H}_{2} \mathrm{O}_{2}$ concentration for the alizarin degradation makes it promising for the system.

As the $\mathrm{pH}$ of the reaction plays an important role, varying $\mathrm{pH}$ of $3,4,6,8$ and 10 were used to study the effect of $\mathrm{pH}$ on degradation of alizarin. Hydrogen peroxide and $\mathrm{Fe}^{2+}$ show

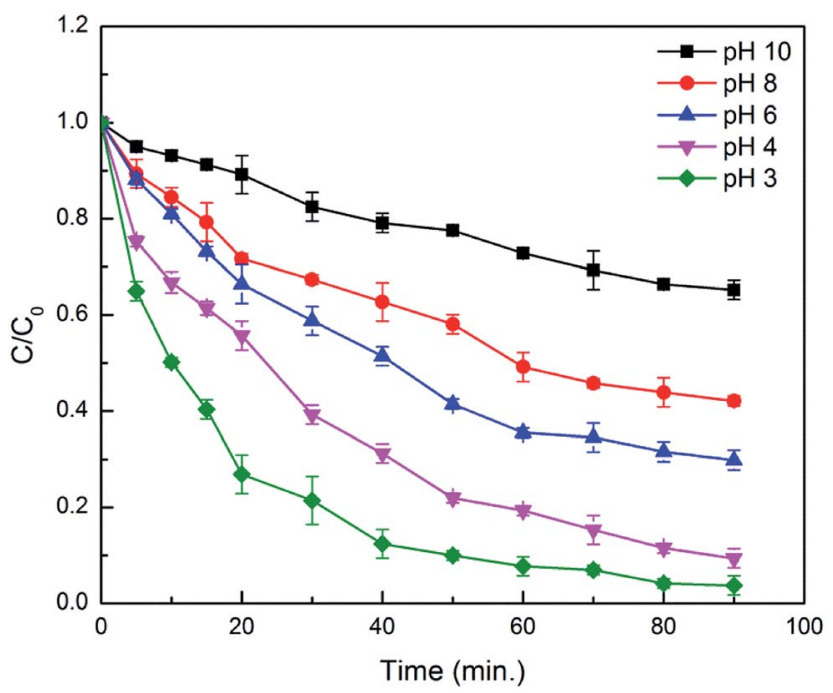

Fig. 9 Effect of $\mathrm{pH}$ on degradation of alizarin by CDFMNPs, reaction conditions: $\left[\mathrm{H}_{2} \mathrm{O}_{2}\right]=25 \mathrm{mM}$, catalyst $=2.0 \mathrm{~g} \mathrm{~L}^{-1}$, [alizarin] $=10 \mathrm{mM}$ at room temperature. The experiments were performed in triplicate and error bars show the standard deviation for the analyses. 


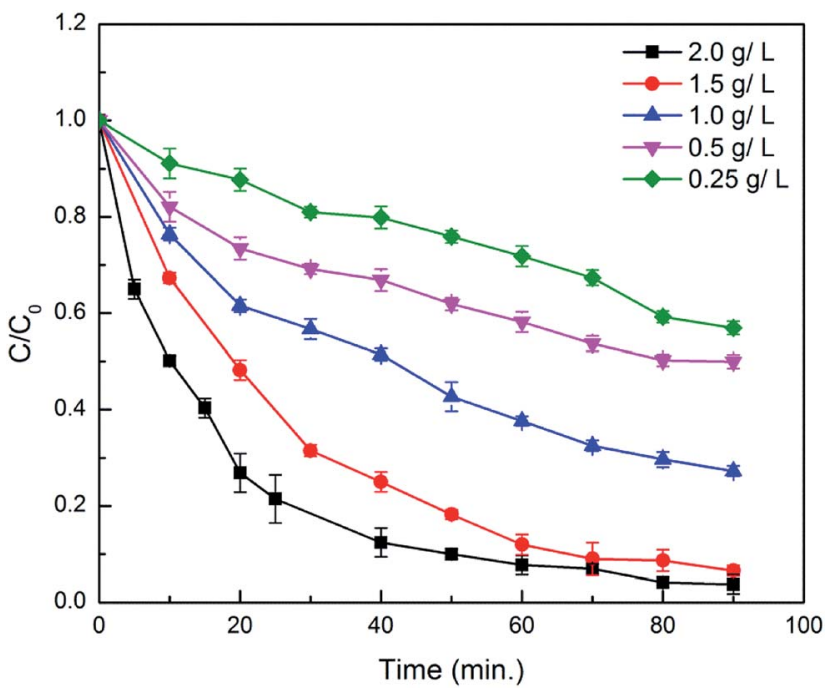

Fig. 10 Effect of catalyst amount on degradation of alizarin by CDFMNPs, reaction conditions: $\left[\mathrm{H}_{2} \mathrm{O}_{2}\right]=25 \mathrm{mM}, \mathrm{pH}=3$, [alizarin] $=$ $10 \mathrm{mM}$ at room temperature. The experiments were performed in triplicate and error bars show the standard deviation for the analyses.

better stability at $\mathrm{pH}$ lower than 3.5 , consequently, give more efficiency at lower pH. ${ }^{21,47}$ Moreover, stability of $\mathrm{Fe}^{2+}$ ions decreases above $\mathrm{pH} 4$ and converted to $\mathrm{Fe}^{3+}$ and can form intermediate hydroxo complexes. ${ }^{11}$ It was found from Fig. 9 \& S8 (ESI $\dagger$ ) that at $\mathrm{pH}$ value of 3 degradation efficiency was maximum, decrease from $\mathrm{pH} 4$ to 8 and considerably decreases after $\mathrm{pH} 8$. The order of decreasing efficiency was: $\mathrm{pH} 3<\mathrm{pH} 4<$ pH $6<\mathrm{pH} 8<\mathrm{pH} 10$. The higher degradation efficiency at pH 3 is due to the production of more number of reactive ${ }^{\circ} \mathrm{OH}$ radical in acidic conditions than other $\mathrm{pH}$ range, confirms the effectiveness of Fenton reaction at lower $\mathrm{pH}$ range.

Similarly, the Fig. 10 shows the effect of varied amount of catalyst from $0.25-2.0 \mathrm{~g} \mathrm{~L}^{-1}$ on the degradation of alizarin and it was found that the $2.0 \mathrm{~g} \mathrm{~L}^{-1}$ catalyst shows the maximum degradation under above mentioned reaction conditions at room temperature. The trend of increasing the degradation with catalyst loading is due to the increase in active sites which acted as peroxidase like catalyst to generate hydroxyl radicals from $\mathrm{H}_{2} \mathrm{O}_{2}$. The excess of catalyst loading decreases the production of hydroxyl radicals by adsorbing $\mathrm{H}_{2} \mathrm{O}_{2}$ on the surface of the catalyst thereby decreasing the degradation rate of 4-chlorophenol at optimum $\mathrm{H}_{2} \mathrm{O}_{2}$ concentrations by $\mathrm{Fe}_{3} \mathrm{O}_{4} @ \beta$-CD. ${ }^{48}$ Moreover, increasing catalyst loading decreases the density of surface adsorbed $\mathrm{H}_{2} \mathrm{O}_{2}$ for hydroxyl radical production since the degradation reaction believed to be occurring on the surface of the catalyst. Again, agglomeration of nanoparticles due to excessive catalyst loading is another reason of decreasing hydroxy radical production in most of heterogeneous Fenton reactions. ${ }^{48-50}$

The metal components in the catalyst framework are considered to play the vital role in catalytic reactions. ${ }^{5}$ Similarly, in our work also the degradation reaction depends on the metal sites in the catalyst framework, so it is necessary to analyze the stability of the catalysts in liquid-phase oxidation. The leaching of $\mathrm{Fe}^{2+}$ and total dissolved iron in solution was determined for the CMFMNPs and results were shown in the Fig. 11(a). It is important to determine the iron dissolution, as it is directly related to the catalytic activity of the catalyst, in acidic condition as it favours the process in comparison to neutral or basic conditions. ${ }^{51}$ The leaching experiments were carried out in optimum Fenton oxidation reaction conditions of the alizarin degradation for $2.0 \mathrm{~g} \mathrm{~L}^{-1}$ catalyst. Other reaction parameters were: alizarin concentration $10 \mathrm{mM}, \mathrm{H}_{2} \mathrm{O}_{2} 25 \mathrm{mM}, \mathrm{pH} 3$ at room temperature. From the Fig. 11(a), it can be seen that leaching of ferrous ion steadily increased up to $3.8 \mathrm{mg} \mathrm{L}^{-1}$ at $30 \mathrm{~min}$, suggested the faster Fenton process and then decreased to $2.4 \mathrm{mg} \mathrm{L}^{-1}$ at $100 \mathrm{~min}$. At this stage the oxidative process is further enhanced by the hydroxylated form of fullerene called fullerol by producing more ROS. ${ }^{52}$ Simultaneously, the total dissolved iron in the solution increases continuously and attained the value of $7.1 \mathrm{mg} \mathrm{L}^{-1}$ at $100 \mathrm{~min}$. The continuously increased dissolved iron value was due to the combined dissolution of ferrous and ferric irons from the CDFMNPs catalyst. The observed values were less than the previously reported values of our iron leaching for $\mathrm{Fe}_{3} \mathrm{O}_{4}-\mathrm{CeO}_{2}$ composite, ${ }^{18}$ where $\mathrm{Fe}^{2+}$ ions were oxidized to $\mathrm{Fe}^{3+}$ ions and form intermediate $\mathrm{Fe}(\mathrm{III})$ complexes. It could be expected that the initial release of
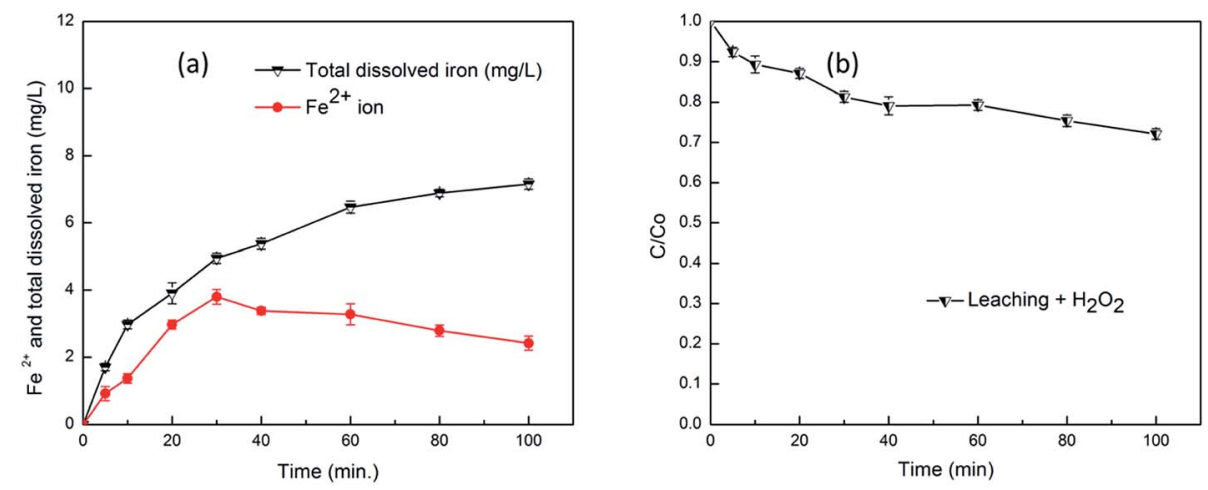

Fig. 11 (a) Concentration of $\mathrm{Fe}^{2+}$ ion and total dissolved iron, reaction conditions: catalyst $=2.0 \mathrm{~g} \mathrm{~L}^{-1}$, [alizarin] $=10 \mathrm{mM},\left[\mathrm{H}_{2} \mathrm{O}_{2}\right]=25 \mathrm{mM}, \mathrm{pH}=$ 3 at room temperature. (b) Alizarin degradation efficiency catalyzed by Fe leaching. The experiments were performed in triplicate and error bars show the standard deviation for the analyses. 
ferrous ion from CDFMNPs was due to the oxidation by $\mathrm{H}_{2} \mathrm{O}_{2}$ and decreasing trend was due to the conversion of ferrous to ferric ion, which results the increases of $\mathrm{Fe}^{2+}$ and $\mathrm{Fe}^{3+}$ (total dissolved iron).

The homogeneous phase reaction was also performed after the heterogeneous process optimization was done. For a homogeneous reaction to occur, the CDFMNPs catalyst was stirred in a reaction mixture and removed by an external magnet after $100 \mathrm{~min}$. Then the alizarin was added into the reaction mixture, containing leached iron, with $200 \mu \mathrm{L}$ of $\mathrm{H}_{2} \mathrm{O}_{2}$ to initiate the reaction. From Fig. 11(b), it can be seen that only $21 \%$ of alizarin was degraded within $1 \mathrm{~h}$ because of the iron leaching in
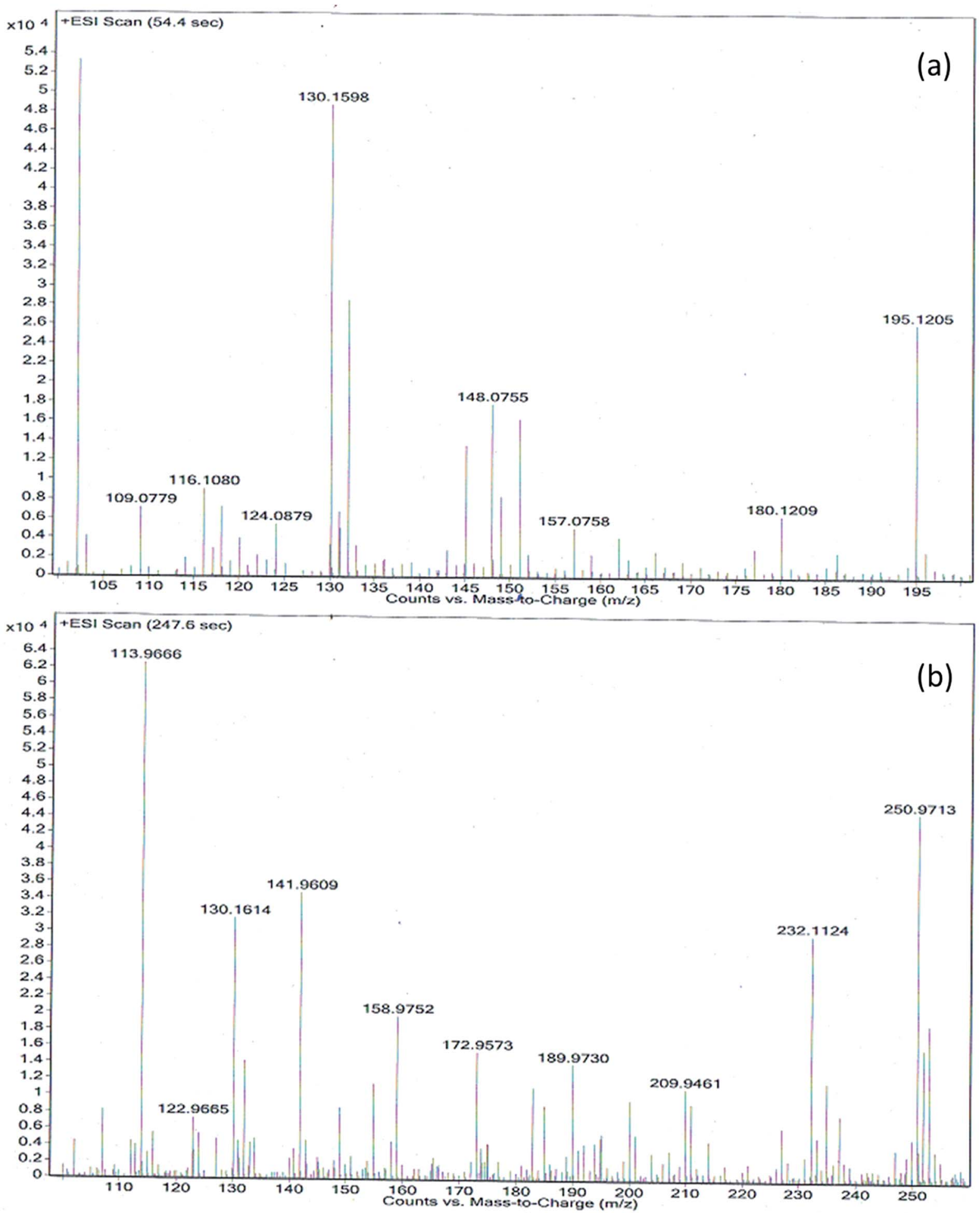

Fig. 12 (a and b) LC-MS [ESI (+) ve mode] spectra of degraded alizarin by $\beta$-CD-fullerene $/ \mathrm{Fe}_{3} \mathrm{O}_{4}$ (CDFMNPs). 
a homogenous manner, value increased a bit to $28 \%$ after $100 \mathrm{~min}$ of reaction time. So, the degradation of alizarin is predominantly due to the heterogeneous Fenton process with a minor contribution from homogeneous process. The feasibility of heterogeneous process was supported by stabilizing effect of fullerene and enhanced activity of $\beta$-CD. The aggregation or incorporation of fullerene onto iron oxide in solution greatly effects the morphology of the composite thereby implications on reactivity and enhance the stability of the system. The interaction of fullerene with iron oxide nanoparticles produces ordered assemblies along with amorphous aggregates with short range periodic structures during immobilization. ${ }^{8}$ In magnetite Fe cations occupy the tetrahedral and octahedral sites within the cubic inverse spinal structure of it. The $\mathrm{Fe}^{2+}$ and $\mathrm{Fe}^{3+}$ both occupy the octahedral sites and retaining the crystal structure during the reversible oxidation and reduction of $\mathrm{Fe}$ species. These structural features make it efficient for degrading dyes from aqueous solutions by using the electrogeneration of Fenton catalysts. ${ }^{\mathbf{4 4}}$

\subsection{ESI mass analysis of alizarin}

Liquid chromatography mass spectroscopic (LCMS) study in positive ion mode was performed to know the product formed in degradation reaction by analyzing the alizarin solution after the reaction. The molecular ion peak of alizarin at $\mathrm{m} / \mathrm{z} 240$ was not observed after degradation by CDFMNPs, instead we observed a number of different peaks in different interval of time as shown in the Fig. 12(a and b) and S9 (ESI $\dagger$ ). The oxidation of alizarin followed a complex path and started with the reactive ${ }^{\circ} \mathrm{OH}$ radical attack. Upon oxidation with $\mathrm{H}_{2} \mathrm{O}_{2}$ and catalyst it loses its two hydroxyl groups one by one to produce

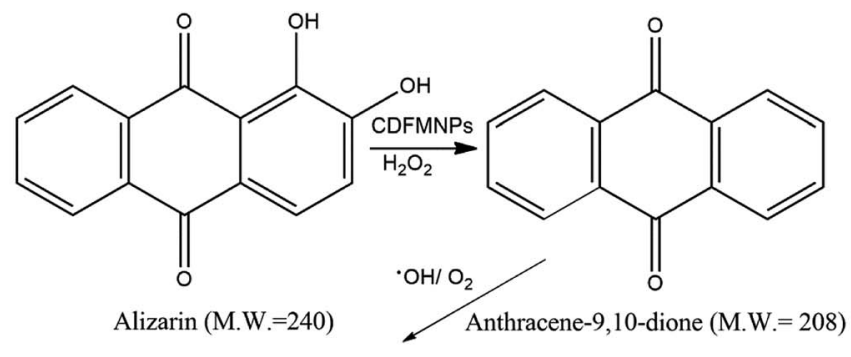

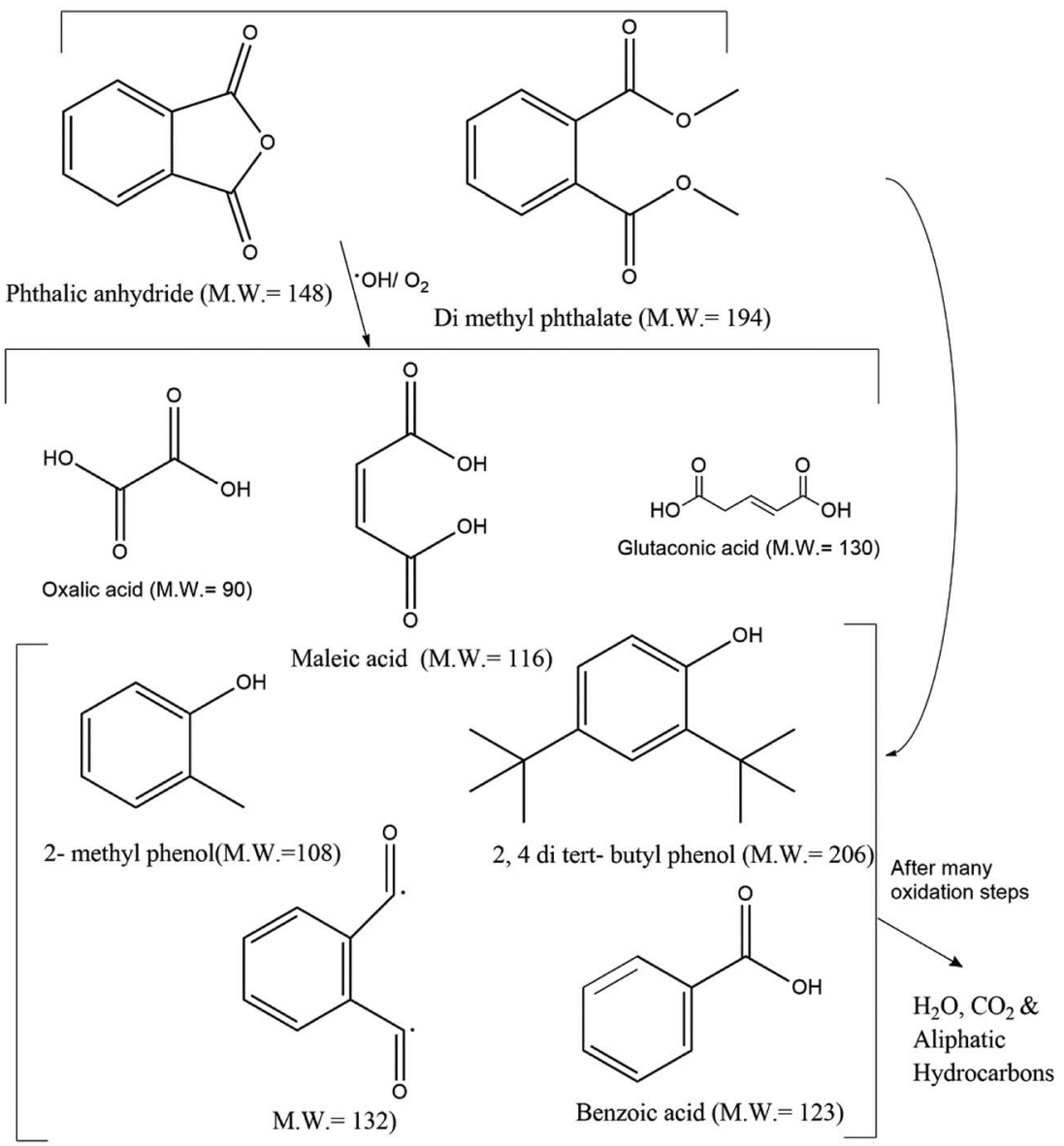

Fig. 13 Proposed reaction scheme for the degradation of alizarin, based on the LCMS data, to phthalic anhydride and di methyl phthalate, further oxidation to aliphatic acids and monocyclic products. Finally, after many oxidation steps to aliphatic hydrocarbons, $\mathrm{H}_{2} \mathrm{O}$ and $\mathrm{CO}_{2}$. 
Table 1 Reusability of CDFMNPs catalyst on degradation of alizarin $^{a}$

\begin{tabular}{llrrr}
\hline Number of cycle & First & Second & Third & Forth \\
\hline $\begin{array}{l}\text { Degradation (\%) of alizarin } \\
\text { Retained activity (\%) }\end{array}$ & $93.2 \pm 1.5$ & $91.4 \pm 2.1$ & $88.1 \pm 1.8$ & $85.3 \pm 2.1$ \\
\hline
\end{tabular}

${ }^{a}$ Reaction conditions: $\left[\mathrm{H}_{2} \mathrm{O}_{2}\right]=25 \mathrm{mM}$, [alizarin] $=10 \mathrm{mM}$, catalyst $=2.0 \mathrm{~g} \mathrm{~L}^{-1}, \mathrm{pH}=3$ at room temperature. The experiments were performed in triplicate and the values are presented as means and standard deviation.

anthracene-9,10-dione (208 amu) and produced $[\mathrm{M}+1]^{+}$peak at $\mathrm{m} / \mathrm{z} 209$, intake its parent ring structure. In the next step ring cleavage took place to produce monocyclic aromatic product viz. dimethyl phthalate (194 amu) and phthalic anhydride (148 amu) corresponds to $[\mathrm{M}+1]^{+}$peak with $\mathrm{m} / \mathrm{z}$ at 195 and $[\mathrm{M}]^{+}$peak with $\mathrm{m} / \mathrm{z}$ at 148 respectively. Further oxidation of the products give $[\mathrm{M}]^{+}$peak at $\mathrm{m} / \mathrm{z} 116$ and at $\mathrm{m} / \mathrm{z} 130,\left[\mathrm{M}^{+}+\mathrm{Na}\right.$ ] peaks at $\mathrm{m} / \mathrm{z}$ 113 corresponds to maleic acid (116 amu), glutaconic acid (130 $\mathrm{amu})$ and oxalic acid (90 amu) respectively. Additionally, other degraded products of alizarin with monocyclic ring are, $\mathrm{m} / \mathrm{z}$ at 207 for 2,4-di-tert-butyl phenol (206 amu), $\mathrm{m} / \mathrm{z}$ at 123 for benzoic acid $(123 \mathrm{amu})$. Benzoic acid appeared as $[\mathrm{M}]^{+}$peak and other two products appeared in mass spectra as $[\mathrm{M}+1]^{+}$peak. Another $[\mathrm{M}+1]^{+}$peak with $\mathrm{m} / z$ at 109 can be identified as 2methyl phenol (108 amu). The peak at $m / z 113$ for oxalic acid after combination with $\mathrm{Na}^{+}$to appear as $\left[\mathrm{M}^{+}\right]^{+}$ion peak, as in ESI-(+)ve mode formation of sodium adduct is very common. At $18.6 \mathrm{~s}$ we observed only three prominent peaks in the mass spectra (Fig. S9 of ESI $\dagger$ ) for benzoic acid $(m / z=123)$, dimethyl phthalate $(m / z=195)$ and compound with $m / z 133$, which could be a radical intermediate with M.W. 132. Since the degradation of alizarin in the presence of $\mathrm{H}_{2} \mathrm{O}_{2}$ by CDFMNPs is an oxidative process, it produces a few degraded products which could not be identified and may be appeared because of the produced from solvent or contamination. However, it is proved from the observed data that aromatic ring structure of the alizarin was destroyed or reduced by CDFMNPs and it is expected that after a number of oxidative steps all aromatic rings opened up to form small molecules like $\mathrm{H}_{2} \mathrm{O}$ and $\mathrm{CO}_{2}$ and aliphatic hydrocarbons, which could not be identified by LC-MS study. ${ }^{53}$

Probable degradation pathway of alizarin by Fenton system of CDFMNPs $/ \mathrm{H}_{2} \mathrm{O}_{2}$ is depicted in Fig. 13, though the mechanism of heterogeneous Fenton process is not certain. ${ }^{54}$ During the multistep oxidative destruction process, ${ }^{\circ} \mathrm{OH}$ radical first produced dimethyl phthalate and phthalic anhydride after removal of two hydroxyl groups from alizarin. Further, oxidation executes the complete decolourization of alizarin and believed that after many oxidative steps cleavage of the aromatic ring take place to produce acids and different small molecules.

\subsection{Reusability and recovery of the catalyst}

It is important for a solid catalyst to be recovered after reaction and reused for a fresh set of experiment. The CDFMNPs can be easily recovered after every reaction with an external magnet (Fig. 3, inset) which was confirmed from its magnetization value as shown in VSM study. After every set of experiment catalyst was magnetically recovered, washed several times with ethanol and deionized water to remove any organic products and unreacted precursors. Then it was used for five consecutive runs. Table 1 shows the degradation efficiency and retained activity of the catalyst for alizarin. It was found that catalyst shown remarkable stability after a fifth run from about $93.2 \%$ to $80.2 \%$ degradation. The insignificant decrease of alizarin degradation and minor loss of catalytic activity is due to the deactivation of the catalyst by $\mathrm{Fe}(\mathrm{III})$ complex formation, nominal iron leaching from the catalyst surface and the catalyst lost during recovery process. Overall, catalyst has shown a significant activity under the studied experimental reaction conditions.

\section{Conclusions}

We have presented here the synthesis of FMNPs and CDFMNPs with a simple method. The CDFMNPs show excellent activity towards alizarin degradation at optimum reaction conditions. The addition of fullerene has enhanced the activity of the magnetic composite with nominal iron leaching whereas coating of $\beta$-CD alters the crystalline nature, magnetic property and most importantly the surface activity of the catalyst. The oxidative degradation process predominantly occurs in heterogeneous manner as confirmed by quantification of insignificant amount of leached iron in solution. Because of these combined effects of fullerene and $\beta$-CD with magnetic nature of $\mathrm{Fe}_{3} \mathrm{O}_{4}$, this catalyst can effectively serve as a heterogeneous Fenton catalyst for the alizarin degradation reaction. Moreover, the catalyst can be separated magnetically and reused without any significant loss of catalytic activity up to five successive uses. These properties make the catalyst more attractive and provide the knowledge-base for future applications in the field of catalysis to understand the degradation mechanism of a wide range of structurally similar textile dyes to alizarin.

\section{Conflicts of interest}

There are no conflicts to declare.

\section{Acknowledgements}

Authors are highly thankful to NEHU, Shillong and Gauhati University, Guwahati for providing instrumental support.

\section{References}

1 A. Kohler, S. Hellweg, B. I. Escher and K. Hungerbühler, Environ. Sci. Technol., 2006, 40, 3395-3401. 
2 J. M. Chacon, M. T. Leal, M. Sánchez and E. R. Bandala, Dyes Pigm., 2006, 69, 144-150.

3 A. C. Pradhan, B. Nanda, K. Parida and M. Das, Dalton Trans., 2013, 42, 558-566.

4 W. Li, R. Wu, J. Duan, C. P. Saint and D. Mulcahy, Chem. Eng. J., 2017, 313, 801-806.

5 Q. Sun, M. Liu, K. Li, Y. Han, Y. Zuo, J. Wang, C. Song, G. Zhang and X. Guo, Dalton Trans., 2016, 45, 7952-7959.

6 E. R. Bandala, M. A. Pelaez, D. D. Dionysiou, S. Gelover, J. Garcia and D. Macías, J. Photochem. Photobiol., A, 2007, 186, 357-363.

7 S. Papic, D. Vujevic, N. Koprivanac and D. Sinko, J. Hazard. Mater., 2009, 164, 1137-1145.

8 S. Ghosh, N. R. Pradhan, H. Mashayekhi, S. Dickert, R. Thantirige, M. T. Tuominen, S. Tao and B. Xing, Environ. Sci. Technol., 2014, 48, 12285-12291.

9 B. Chen, Y. Liu, S. Chen, X. Zhao, W. Yue and X. Pan, Environ. Sci.: Nano, 2016, 3, 670-681.

10 Y. Mu, F. Jia, Z. Ai and L. Zhang, Environ. Sci.: Nano, 2017, 4, 27-45.

11 M. Blanco, A. Martinez, A. Marcaide, E. Aranzabe and A. Aranzabe, Am. J. Anal. Chem., 2014, 5, 490.

12 C. C. Kuan, S.-Y. Chang and S. L. Schroeder, Ind. Eng. Chem. Res., 2015, 54, 8122-8129.

13 B. Kakavandi and A. A. Babaei, RSC Adv., 2016, 6, 84999-85011. 14 P. Tan, Y. Jiang, X.-Q. Liu, D.-Y. Zhang and L.-B. Sun, ACS Sustainable Chem. Eng., 2016, 4, 2223-2231.

15 B. Kalska-Szostko and M. Rogowska, J. Nanosci. Nanotechnol., 2012, 12, 6907-6912.

16 F. Velichkova, C. Julcour-Lebigue, B. Koumanova and H. Delmas, J. Environ. Chem. Eng., 2013, 1, 1214-1222.

17 S. Navalon, M. Alvaro and H. Garcia, Appl. Catal., B, 2010, 99, $1-26$.

18 A. Gogoi, M. Navgire, K. C. Sarma and P. Gogoi, Chem. Eng. J., 2017, 311, 153-162.

19 D. Channei, B. Inceesungvorn, N. Wetchakun, S. Ukritnukun, A. Nattestad, J. Chen and S. Phanichphant, Sci. Rep., 2014, 4, 5757.

20 L. Xu and J. Wang, Environ. Sci. Technol., 2012, 46, 1014510153.

21 R. S. Ribeiro, A. M. Silva, J. L. Figueiredo, J. L. Faria and H. T. Gomes, Appl. Catal., B, 2016, 187, 428-460.

22 N. Jaafarzadeh, B. Kakavandi, A. Takdastan, R. R. Kalantary, M. Azizi and S. Jorfi, RSC Adv., 2015, 5, 84718-84728.

23 P. Nidheesh and R. Rajan, RSC Adv., 2016, 6, 5330-5340.

24 J. Zazo, J. Casas, A. Mohedano and J. Rodríguez, Appl. Catal., $B, 2006,65,261-268$.

25 A. Rodriguez, G. Ovejero, J. Sotelo, M. Mestanza and J. Garcia, Ind. Eng. Chem. Res., 2009, 49, 498-505.

26 Z. D. Meng, L. Zhu, J. G. Choi, M. L. Chen and W. C. Oh, J. Mater. Chem., 2011, 21, 7596-7603.

27 J. A. Rodriguez, I. S. Ibarra, J. M. Miranda, E. Barrado and E. M. Santos, Anal. Methods, 2016, 8, 8466-8473.

28 H. Keypour, M. Noroozi and A. Rashidi, J. Nanostruct. Chem., 2013, 3, 45.
29 G. H. Lee, S. H. Huh, J. W. Jeong and H. C. Ri, J. Magn. Magn. Mater., 2002, 246, 404-411.

30 E. Erdim, A. R. Badireddy and M. R. Wiesner, J. Hazard. Mater., 2015, 283, 80-88.

31 X. Sun, C. Zheng, F. Zhang, L. Li, Y. Yang, G. Wu and N. Guan, J. Phys. Chem. C, 2008, 112, 17148-17155.

32 J. Zhu, P. C. Wang and M. Lu, J. Braz. Chem. Soc., 2013, 24, 171-176.

33 J. Hu, D. Shao, C. Chen, G. Sheng, J. Li, X. Wang and M. Nagatsu, J. Phys. Chem. B, 2010, 114, 6779-6785.

34 S. Lv, Y. Song, Y. Song, Z. Zhao and C. Cheng, Appl. Surf. Sci., 2014, 305, 747-752.

35 R. Chalasani and S. Vasudevan, ACS Nano, 2013, 7, 40934104.

36 Y. Kang, L. Zhou, X. Li and J. Yuan, J. Mater. Chem., 2011, 21, 3704-3710.

37 C. Ahn, X. Zeng, L. Li and S. K. Obendorf, Fashion and Textiles, 2014, 1, 22.

38 C. Ahn, X. Zeng and S. K. Obendorf, Journal of the Korean Society of Clothing and Textiles, 2013, 37, 827-836.

39 S. Pirillo, F. S. G. Einschlag, E. H. Rueda and M. L. Ferreira, Ind. Eng. Chem. Res., 2010, 49, 6745-6752.

$40 \mathrm{H}$. Tamura, K. Goto, T. Yotsuyanagi and M. Nagayama, Talanta, 1974, 21, 314-318.

41 P. Feng, X. Guan, Y. Sun, W. Choi, H. Qin, J. Wang, J. Qiao and L. Li, J. Environ. Sci., 2015, 31, 175-183.

42 C. Hui, C. Shen, T. Yang, L. Bao, J. Tian, H. Ding, C. Li and H. J. Gao, J. Phys. Chem. C, 2008, 112, 11336-11339.

43 M. E. Navgire, P. Gogoi, B. Mallesham, A. Rangaswamy, B. M. Reddy and M. K. Lande, $R S C$ Adv., 2016, 6, 2867928687.

44 G. S. Martinez, G. R. Morales, E. M. Campo, R. Romero, B. A. F. Uribe and R. Natividad, Electrochim. Acta, 2016, 195, 246-256.

45 H. E. Ghandoor, H. Zidan, M. M. Khalil and M. Ismail, Int. J. Electrochem. Sci., 2012, 7, 5734-5745.

46 J. Lee, Y.-H. Choa, J. Kim and K. H. Kim, IEEE Trans. Magn., 2011, 47, 2874-2877.

47 P. Nidheesh, RSC Adv., 2015, 5, 40552-40577.

48 M. Wang, G. Fang, P. Liu, D. Zhou, C. Ma, D. Zhang and J. Zhan, Appl. Catal., B, 2016, 188, 113-122.

49 X. Hu, B. Liu, Y. Deng, H. Chen, S. Luo, C. Sun, P. Yang and S. Yang, Appl. Catal., B, 2011, 107, 274-283.

50 R. Huang, Z. Fang, X. Yan and W. Cheng, Chem. Eng. J., 2012, 197, 242-249.

51 E. Matei, C. Predescu, A. Berbecaru, A. Predescu and R. Trusca, Digest Journal of Nanomaterials and Biostructures, 2011, 6, 1701-1708.

52 E. M. Hotze, T. Phenrat and G. V. Lowry, J. Environ. Qual., 2010, 39, 1909-1924.

53 B. Lai, Y. Zhou, J. Wang, Z. Yang and Z. Chen, Chemosphere, 2013, 93, 2805-2813.

54 A. Gogoi and K. C. Sarma, Mater. Chem. Phys., 2017, 194, 327-336. 